\title{
Influence of a 60-hour Fast on Insulin-mediated Splanchnic and Peripheral Glucose Metabolism in Humans
}

\author{
Ola Björkman and Ljusk Siw Eriksson \\ Departments of Clinical Physiology and Medicine, Huddinge University Hospital, S-141 86 Huddinge, Sweden
}

\begin{abstract}
A brief period of starvation (2-3 d) depletes the hepatic glycogen stores but results in only a limited reduction of the muscle glycogen depots. In this situation insulin resistance contributes to the glucose intolerance, but it is not known which tissue or tissues are responsible for the decreased insulin sensitivity. The present study was therefore undertaken to examine the influence of a 60 -h fast on insulin sensitivity in splanchnic and peripheral tissues in normal humans. Euglycemic (95 mg/dl) 1-mU insulin and hyperglycemic (215-225 mg/dl) glucose clamp studies were conducted for $2 \mathrm{~h}$ in overnight (12 h) and prolonged $(60 \mathrm{~h})$ fasted nonobese subjects. Splanchnic exchange of glucose and gluconeogenic precursors was measured using the hepatic vein catheter technique.

During the euglycemic clamp, insulin infusion resulted in similar steady state insulin levels in 60-h and 12-h fasted subjects $(73 \pm 7$ vs. $74 \pm 5 \mu \mathrm{U} / \mathrm{ml})$. Total glucose disposal was reduced by $45 \%$ after $60 \mathrm{~h}$ of fasting (4.0 \pm 0.3 vs. $7.6 \pm 1.1$ $\mathrm{mg} / \mathrm{kg}$ per min, $P<0.05$ ) and the splanchnic glucose balance reverted from a net release in the basal state (12 h fast, $-1.7 \pm 0.2$, and $60-\mathrm{h}$ fast, $-0.9 \pm 0.1 \mathrm{mg} / \mathrm{kg}$ per $\mathrm{min}, P<0.01$ ) to a net uptake during the clamps that was similar after $60 \mathrm{~h}$ and $12 \mathrm{~h}$ of fasting $(0.6 \pm 0.1 \mathrm{vs} .0 .6 \pm 0.2 \mathrm{mg} / \mathrm{kg}$ per $\mathrm{min})$.

During the hyperglycemic clamp, insulin levels rose rapidly in all subjects. In the 12-h fasted group this rise was followed by a further gradual one, reaching significantly higher values than in 60-h fasted subjects during the second hour $(67 \pm 15$ vs. $25 \pm 2 \mu \mathrm{U} / \mathrm{ml}, P<0.05)$. Total glucose disposal was lower, though not significantly so, after the $60-\mathrm{h}$ fast $(2.6 \pm 0.4 \mathrm{vs}$. $5.4 \pm 1.3 \mathrm{mg} / \mathrm{kg}$ per $\mathrm{min}, 0.05<P<0.10$ ), and as with the euglycemic clamp, the splanchnic glucose balance was altered from a basal net release to a net uptake during the clamp (1.3 \pm 0.2 vs. $1.1 \pm 0.2 \mathrm{mg} / \mathrm{kg}$ per $\mathrm{min}$ ).

After an overnight fast, splanchnic lactate uptake fell and the arterial lactate concentration rose in response to both hyperglycemia and hyperinsulinemia, whereas these variables were unchanged in the 60-h fasted subjects during both types of clamp studies.
\end{abstract}

This work was presented in part at the 19th Annual Meeting of the European Association for the Study of Diabetes, Oslo, Norway.

Address correspondence to Dr. Björkman, Department of Physiology, Medical Science Building, Room 3358, University of Toronto, Ontario M5S 1A8, Canada. Address reprint requests to Dr. Björkman, Department of Clinical Physiology, Huddinge Hospital, S-141 86 Huddinge, Sweden.

Received for publication 22 October 1984 and in revised form 11 March 1985.

J. Clin. Invest.

(c) The American Society for Clinical Investigation, Inc.

$0021-9738 / 85 / 07 / 0087 / 06 \$ 1.00$

Volume 76 , July $1985,87-92$
We conclude that peripheral tissues are predominantly responsible for the insulin resistance seen in starvation. In contrast, net splanchnic glucose uptake in response to hyperinsulinemia and/or hyperglycemia remains unchanged during starvation, despite the depletion of the hepatic glycogen stores.

\section{Introduction}

In the postabsorptive overnight fasted state, hepatic glycogenolysis accounts for the major part of glucose production, while only some $25 \%$ derives from hepatic gluconeogenesis (1). After 2-3 d of fasting the glycogen depots in the liver are exhausted (2), gluconeogenesis is almost exclusively responsible for glucose production $(1,3,4)$, and the circulating glucose levels in peripheral blood are reduced. The adaptation to this situation is known to include both a reduced insulin secretion $(5,6)$ and a reduced sensitivity to insulin $(7)$, but the site of the latter has not been established.

When the hepatic glycogen stores are by no means depleted, e.g., after an overnight fast, it is chiefly the peripheral tissues that dispose of intravenously administered glucose. Thus, $>90 \%$ of an intravenous glucose load is taken up by the periphery and only a small fraction by the splanchnic tissues (8). Because glycogen depletion stimulates glucose uptake by muscle $(9,10)$, it might be supposed that exhaustion of the hepatic glycogen stores alters the relative roles of splanchnic and peripheral tissues in glucose disposal by favoring an uptake to the liver.

As this possibility has not been examined, the present study was undertaken to define the site of starvation-induced insulin resistance and to quantitate the relative contributions of splanchnic and peripheral tissues in the disposal of intravenously administered glucose in the prolonged fasted state.

\section{Methods}

Subjects. 17 healthy, nonobese volunteers, 6 female and 11 male, weighing $\sim 69 \mathrm{~kg}$ (range $53-87 \mathrm{~kg}$ ), and being $\sim 173 \mathrm{~cm}$ in height (range 152-192 cm) and $\sim 27 \mathrm{yr}$ old (range 22-34 yr) participated in the studies. Ten subjects were studied during a hyperglycemic glucose clamp (five after $12 \mathrm{~h}$ and five after $60 \mathrm{~h}$ of fasting) and seven during a euglycemic insulin clamp. In the latter group four subjects, one male and three female, were studied both after $12 \mathrm{~h}$ and after $60 \mathrm{~h}$ of fasting and a total of five subjects were investigated after $12 \mathrm{~h}$ and six after $60 \mathrm{~h}$ of fasting. All subjects were informed of the nature, purpose, and possible risks involved in the study before they gave their consent to participate. The protocol was reviewed and approved by the Ethical Committee of Huddinge Hospital.

Procedure. The studies were performed in the morning after an overnight (12-14 h) or 60-64 h fast, with the subjects in the recumbent position. After the administration of local anesthesia, teflon catheters were inserted percutaneously into an antecubital vein and a brachial artery. A Cournand catheter (no. 7 or 8 ) was inserted into a femoral 
vein and advanced under fluoroscopic control to a right-sided hepatic vein. The tip of the catheter was placed $3-4 \mathrm{~cm}$ from the wedged position. After a basal period, infusions of glucose (hyperglycemic glucose clamp) or insulin and glucose (euglycemic insulin clamp) were started. In the hyperglycemic glucose clamp, the plasma glucose concentration was raised to $145 \mathrm{mg} / \mathrm{dl}$ (60-h fasted subjects) or 125 $\mathrm{mg} / \mathrm{dl}$ (12-h fasted subjects) above the basal level by administering a priming infusion of glucose in a logarithmically decreasing manner over $14 \mathrm{~min}$ (11). Based upon arterial plasma glucose determinations obtained at 5-min intervals, the plasma glucose concentration was subsequently maintained at the hyperglycemic plateau by means of a variable infusion of a $20 \%$ glucose solution for $120 \mathrm{~min}$. Urine was collected at the end of the experiment for evaluation of the urinary glucose loss.

In the euglycemic clamp, a 10-min priming infusion of insulin was followed by a constant infusion at a rate of $1 \mathrm{mU} / \mathrm{kg}$ per min for 110 $\mathrm{min}$. In the 60-h fasted subjects the glucose concentration was increased by $25 \mathrm{mg} / \mathrm{dl}$ at the start of the insulin infusion to reach the same glucose concentration as in the overnight fasted subjects. Thus, during the insulin clamp, the arterial glucose concentration was maintained at $90-95 \mathrm{mg} / \mathrm{dl}$ in both groups by means of a variable infusion of $20 \%$ glucose.

Blood samples for analysis of glucose, insulin, ketone bodies, and gluconeogenic substrates were collected from the arterial and hepatic venous catheters in the basal state and at intervals during the infusion. Splanchnic blood flow was measured by the constant infusion technique (12) using indocyanine green dye (13).

Analytical methods. Plasma (Glucostat; Beckman Instruments Inc., Fullerton, CA) and whole blood glucose concentrations (14) were determined with the glucose oxidase reaction. Serum insulin was measured by radioimmunoassay (Pharmacia Diagnostics, Uppsala, Sweden). Lactate (15), pyruvate (16), glycerol (17), acetoacetate, and 3-OH-butyrate (18) were all determined in whole blood using enzymatic methods modified for fluorometry. Indocyanine green dye concentration was determined spectrophotometrically in serum samples.

Calculations. The glucose infusion rate was recorded continuously during each experiment. The amount of glucose metabolized or total glucose disposal (M) was calculated from the glucose infusion rate after correcting for deviations in glucose concentrations and, in the hyperglycemic clamp studies, urinary glucose loss (11). Net splanchnic exchange rates for glucose (SGE) and other substrates were calculated as the product of the arteriovenous concentration differences and the estimated splanchnic blood flow. Peripheral glucose uptake (PGU) was obtained as the difference between total glucose disposal and net splanchnic glucose exchange (PGU $=M-$ SGE).
Standard statistical methods were employed, using the paired $t$ test when applicable (19). Data in text, tables, and figures are given as mean \pm SEM.

\section{Results}

Basal state. Table I presents the arterial concentrations of insulin and glucose and the net splanchnic glucose output. In the basal state the values were on the average $44 \%$ (NS), $32 \%$ $(P<0.001)$, and 50\% $(P<0.01)$ lower, respectively, after 60 $h$ of fasting than in the overnight fasted subjects (both types of clamp study calculated together).

Arterial concentrations and splanchnic exchange of gluconeogenic precursors and ketone bodies are reported separately for the two studies in Tables II and III. In the case of lactate and pyruvate, arterial concentrations and splanchnic exchange were not significantly influenced by $60 \mathrm{~h}$ of fasting. For glycerol, on the other hand, both the arterial concentration and the splanchnic uptake were increased twofold $(P<0.05-0.01)$. The blood levels of ketone bodies were dramatically augmented (acetoacetate $+1,100 \%$ and 3-OH-butyrate $+2,400 \%$, $P<0.001)$ and their splanchnic production increased four- to fivefold $(P<0.02-0.001)$. $60 \mathrm{~h}$ of fasting did not significantly influence estimated splanchnic blood flow.

Euglycemic insulin clamp. In the 60 -h fasted group the glucose concentration was raised abruptly to and maintained at the same level as in the 12-h fasted state (Table I). Infusion of insulin resulted in similar steady state concentrations of insulin $(73 \pm 7$ and $74 \pm 5 \mu \mathrm{U} / \mathrm{ml}$ in the $60-\mathrm{h}$ and $12-\mathrm{h}$ fasted subjects, respectively). The rate of glucose infusion required to maintain the euglycemic level was $45 \%$ lower in the $60-\mathrm{h}$ than in the $12-\mathrm{h}$ fasted state $(4.00 \pm 0.33$ vs. $7.55 \pm 1.10 \mathrm{mg} / \mathrm{kg}$ per min, $P<0.05$, Table I).

In both groups hyperinsulinemia was accompanied by an alteration in splanchnic glucose exchange from a net release in the basal state to a net uptake (Fig. 1, Table I). This response was somewhat delayed in the overnight fasted subjects as compared with the $60-\mathrm{h}$ fasted group, but the resultant splanchnic glucose uptake during the second hour of infusion was similar in the two groups (60-h fast, $0.62 \pm 0.12$, 12-h fast, $0.56 \pm 0.22 \mathrm{mg} / \mathrm{kg}$ per $\mathrm{min}$ ).

Table I. Arterial Glucose and Insulin Concentrations as well as Total Glucose Disposal and Regional Glucose Exchange in the Basal State and during Euglycemic Insulin and Hyperglycemic Glucose Clamps After $12 \mathrm{~h}$ and $60 \mathrm{~h}$ of Fasting

\begin{tabular}{|c|c|c|c|c|c|c|c|}
\hline & & $\begin{array}{l}\text { Arterial } \\
\text { glucose } \\
\text { concentration }\end{array}$ & $\begin{array}{l}\text { Arterial } \\
\text { insulin } \\
\text { concentration }\end{array}$ & $\begin{array}{l}\text { Total glucose } \\
\text { disposal }\end{array}$ & $\begin{array}{l}\text { Splanchnic } \\
\text { glucose } \\
\text { exchange }\end{array}$ & $\begin{array}{l}\text { Splanchnic } \\
\text { glucose } \\
\text { exchange }\end{array}$ & $\begin{array}{l}\text { Peripheral } \\
\text { glucose } \\
\text { uptake* }\end{array}$ \\
\hline & & $m g / 100 m l$ & $\mu U / m l$ & mg/kg per min & $m g / k g$ per min & 90 & $m g / k g$ per min \\
\hline \multirow[t]{2}{*}{ Basal state } & $12 \mathrm{~h}$ & $99 \pm 2$ & $9 \pm 2$ & & $-1.70 \pm 0.23$ & & \\
\hline & $60 \mathrm{~h}$ & $67 \pm 2 \S$ & $5 \pm 1$ & & $-0.85 \pm 0.09 \pi$ & & \\
\hline Euglycemic & $12 \mathrm{~h}$ & $94 \pm 5$ & $74 \pm 5$ & $7.55 \pm 1.10$ & $0.56 \pm 0.22$ & $7 \pm 2$ & $6.98 \pm 0.93$ \\
\hline Insulin clampł & $60 \mathrm{~h}$ & $93 \pm 2$ & $73 \pm 7$ & $4.00 \pm 0.33^{\prime \prime}$ & $0.62 \pm 0.12$ & $15 \pm 2^{\prime \prime}$ & $3.38 \pm 0.26 \pi$ \\
\hline Hyperglycemic & $12 \mathrm{~h}$ & $223 \pm 2$ & $67 \pm 15$ & $5.38 \pm 1.28$ & $1.13 \pm 0.23$ & $16 \pm 9$ & $4.25 \pm 1.33$ \\
\hline Glucose clampł & $60 \mathrm{~h}$ & $212 \pm 2$ & $25 \pm 2^{11}$ & $2.62 \pm 0.39$ & $1.26 \pm 0.20$ & $49 \pm 9$ & $1.42 \pm 0.36$ \\
\hline
\end{tabular}

Data are expressed as mean \pm SEM. * PGU $=\mathrm{M}-\mathrm{SGE}$; M, total glucose disposal; PGU, peripheral glucose uptake; and SGE, splanchnic glucose exchange. ¥ Average values during second hour of the clamp. § Significantly different from the 12-h fasted state, $P<0.001$. "Significantly different from the 12 -h fasted state, $P<0.05$. I Significantly different from the 12 -h fasted state, $P<0.01$. ** Percentage of total glucose disposal. 
Table II. Arterial Concentrations and Splanchnic Exchange of Gluconeogenic Precursors and Ketone Bodies as well as Estimated Splanchnic Blood Flow (ESBF) in the Basal State and during Euglycemic Insulin Clamp After 12 h and $60 \mathrm{~h}$ of Fasting

\begin{tabular}{|c|c|c|c|c|c|}
\hline & & \multicolumn{2}{|c|}{ Arterial concentrations } & \multicolumn{2}{|c|}{ Splanchnic exchange } \\
\hline & & Basal & $\begin{array}{l}\text { Insulin infusion } \\
\text { of } 120 \mathrm{~min}\end{array}$ & Basal & $\begin{array}{l}\text { Insulin infusion } \\
\text { of } 120 \mathrm{~min}\end{array}$ \\
\hline & & mmol/liter & mmol/liter & $\mathrm{mmol} / \mathrm{min}$ & $\mathrm{mmol} / \mathrm{min}$ \\
\hline \multirow[t]{2}{*}{ Lactate } & $12 \mathrm{~h}$ & $0.50 \pm 0.03$ & $0.88 \pm 0.03 \S$ & $0.26 \pm 0.03$ & $0.17 \pm 0.02^{* *}$ \\
\hline & $60 \mathrm{~h}$ & $0.58 \pm 0.02$ & $0.58 \pm 0.03 \ddagger$ & $0.29 \pm 0.03$ & $0.40 \pm 0.05^{*}$ \\
\hline \multirow{2}{*}{ Pyruvate } & $12 \mathrm{~h}$ & $0.05 \pm 0.01$ & $0.07 \pm 0.01^{\prime \prime}$ & $0.01 \pm 0.01$ & $-0.02 \pm 0.01^{* *}$ \\
\hline & $60 \mathrm{~h}$ & $0.04 \pm 0.01$ & $0.04 \pm 0.01$ & $0.02 \pm 0.01$ & $0.04 \pm 0.02 \pi$ \\
\hline \multirow[t]{2}{*}{ Glycerol } & $12 \mathrm{~h}$ & $0.04 \pm 0.01$ & $0.02 \pm 0.01 \S$ & $0.05 \pm 0.01$ & $0.01 \pm 0.01 \S$ \\
\hline & $60 \mathrm{~h}$ & $0.09 \pm 0.01^{*}$ & $0.06 \pm 0.01 \pi$ & $0.10 \pm 0.02 \pi$ & $0.05 \pm 0.01^{* *-\pi}$ \\
\hline \multirow{2}{*}{$\begin{array}{l}\text { Acetoacetic } \\
\text { acid }\end{array}$} & $12 \mathrm{~h}$ & $0.06 \pm 0.01$ & $0.02 \pm 0.01^{* *}$ & $-0.08 \pm 0.01$ & $-0.01 \pm 0.01^{11}$ \\
\hline & $60 \mathrm{~h}$ & $0.72 \pm 0.06 \ddagger$ & $0.17 \pm 0.05 \S \pi$ & $-0.40 \pm 0.04 \ddagger$ & $-0.15 \pm 0.05 \pi$ \\
\hline \multirow[t]{3}{*}{ 3-OH-Butyrate } & $12 \mathrm{~h}$ & $0.12 \pm 0.03$ & $0.01 \pm 0.01^{* *}$ & $-0.10 \pm 0.02$ & $0.00 \pm 0.01^{\prime \prime}$ \\
\hline & $60 \mathrm{~h}$ & $2.96 \pm 0.40 \ddagger$ & $0.30 \pm 0.11 \S \pi$ & $-0.37 \pm 0.09$ \ & $-0.06 \pm 0.04^{* *}$ \\
\hline & & & & liter/min & liter/min \\
\hline \multirow[t]{2}{*}{ ESBF } & $12 \mathrm{~h}$ & & & $1.40 \pm 0.11$ & $1.22 \pm 0.15$ \\
\hline & $60 \mathrm{~h}$ & & & $1.39 \pm 0.03$ & $1.37 \pm 0.07$ \\
\hline
\end{tabular}

Data are expressed as mean \pm SEM. * Significantly different from 12 -h fasted state, $P<0.01$. ¥ Significantly different from 12 -h fasted state, $P<0.001$. § Significantly different from basal, $P<0.001$. "Significantly different from basal, $P<0.01$. I Significantly different from $12-\mathrm{h}$ fasted state, $P<0.05$. ${ }^{* *}$ Significantly different from basal, $P<0.05$.

Peripheral glucose uptake during the clamp (calculated as the difference between total glucose disposal and net splanchnic glucose uptake) was $50 \%$ lower after the 60 -h fast compared with after the $12-\mathrm{h}$ fast $(3.38 \pm 0.26$ vs. $6.98 \pm 0.93 \mathrm{mg} / \mathrm{kg}$ per $\min , P<0.01$ ).

In the 12-h fasted state, hyperinsulinemia was accompanied

Table III. Arterial Concentrations and Splanchnic Exchange of Gluconeogenic Precursors and Ketone Bodies as well as Estimated Splanchnic Blood Flow (ESBF) in the Basal State and during Hyperglycemic Glucose Clamp After $12 \mathrm{~h}$ and $60 \mathrm{~h}$ of Fasting

\begin{tabular}{|c|c|c|c|c|c|}
\hline & & \multicolumn{2}{|c|}{ Arterial concentrations } & \multicolumn{2}{|c|}{ Splanchnic exchange } \\
\hline & & Basal & $\begin{array}{l}\text { Glucose infusion } \\
\text { of } 120 \mathrm{~min}\end{array}$ & Basal & $\begin{array}{l}\text { Glucose infusion } \\
\text { of } 120 \mathrm{~min}\end{array}$ \\
\hline & & mmol/liter & mmol/liter & $\mathrm{mmol} / \mathrm{min}$ & $\mathrm{mmol} / \mathrm{min}$ \\
\hline \multirow[t]{2}{*}{ Lactate } & $12 \mathrm{~h}$ & $0.39 \pm 0.01$ & $0.79 \pm 0.08 \ddagger$ & $0.27 \pm 0.03$ & $0.16 \pm 0.03$ \\
\hline & $60 \mathrm{~h}$ & $0.57 \pm 0.02^{*}$ & $0.56 \pm 0.05 \S$ & $0.29 \pm 0.03$ & $0.35 \pm 0.07 \S$ \\
\hline \multirow[t]{2}{*}{ Pyruvate } & $12 \mathrm{~h}$ & & & & \\
\hline & $60 \mathrm{~h}$ & $0.03 \pm 0.01$ & $0.04 \pm 0.01$ & $0.02 \pm 0.01$ & $0.03 \pm 0.01$ \\
\hline \multirow[t]{2}{*}{ Glycerol } & $12 \mathrm{~h}$ & & & & \\
\hline & $60 \mathrm{~h}$ & $0.07 \pm 0.01$ & $0.06 \pm 0.01$ & $0.06 \pm 0.02$ & $0.06 \pm 0.02$ \\
\hline \multirow[t]{2}{*}{ Acetoacetate } & $12 \mathrm{~h}$ & & & & \\
\hline & $60 \mathrm{~h}$ & $0.75 \pm 0.11$ & $0.47 \pm 0.18 \ddagger$ & $-0.31 \pm 0.05$ & $-0.27 \pm 0.12$ \\
\hline \multicolumn{6}{|c|}{ 3-OH-Butyrate $12 \mathrm{~h}$} \\
\hline & $60 \mathrm{~h}$ & $3.3 \pm 0.07$ & $0.9 \pm 0.4^{\|}$ & $-0.39 \pm 0.03$ & $-0.03 \pm 0.03^{\prime \prime}$ \\
\hline & & & & liter/min & liter/min \\
\hline \multirow[t]{2}{*}{ ESBF } & $12 \mathrm{~h}$ & & & $1.60 \pm 0.15$ & $0.42 \pm 0.02$ \\
\hline & $60 \mathrm{~h}$ & & & $1.43 \pm 0.21$ & $1.46 \pm 0.33$ \\
\hline
\end{tabular}

Data are expressed as mean \pm SEM. * Significantly different from 12-h fasted state, $P<0.001$. $¥$ Significantly different from basal, $P<0.05$. $\S$ Significantly different from 12 -h fasted state, $P<0.05$. "Significantly different from basal, $P<0.01$. 

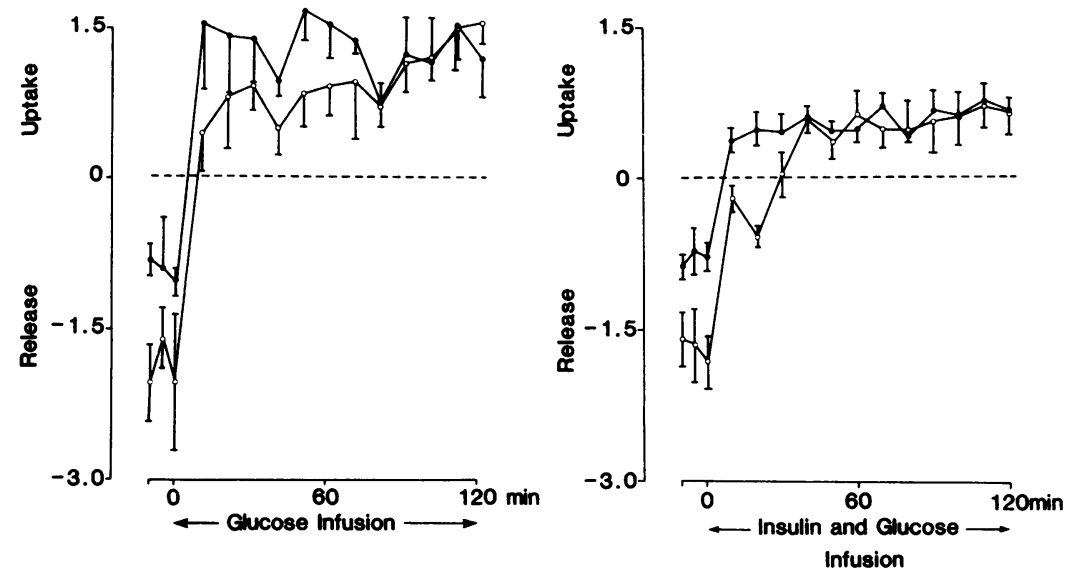

Figure 1. Influence of hyperglycemia (left) and hyperinsulinemia (right) on net splanchnic glucose exchange ( $\mathrm{mg} / \mathrm{kg}$ per $\mathrm{min}$ ) in $12-\mathrm{h}$ (open circles) and 60-h (filled circles) fasted subjects. by decreased splanchnic uptakes and augmented arterial concentrations of lactate and pyruvate $(P<0.05$ and $P<0.01-$ 0.001 , respectively). In contrast, in the 60 -h fasted state neither the splanchnic exchange nor the arterial concentrations of these substrates were influenced by insulin administration, resulting in significantly higher and lower values, respectively, during insulin infusion than in 12-h fasted subjects (Table II).

The arterial concentration and the splanchnic uptake of glycerol both fell in response to insulin infusion. The absolute fall was similar in $12-\mathrm{h}$ and $60-\mathrm{h}$ fasted subjects, but the resulting values at $120 \mathrm{~min}$ of infusion were higher in the 60 $h$ fasted group $(P<0.05)$. In both groups, the arterial concentration and splanchnic production of acetoacetate and 3-OHbutyrate fell in response to insulin infusion. Nevertheless, except for splanchnic 3-OH-butyrate production, these variables showed significantly higher values during insulin infusion in the 60-h fasted state. Estimated splanchnic blood flow was not significantly influenced by hyperinsulinemia in either group.

Hyperglycemic glucose clamp. During the hyperglycemic glucose clamp, the plasma glucose concentration was raised and maintained at $212 \pm 2$ and $223 \pm 2 \mathrm{mg} / \mathrm{dl}$ in the $60-\mathrm{h}$ and 12-h fasted subjects, respectively $(P<0.01$, Table I, Fig. 2 ). This rise was accompanied by a rapid increase in insulin concentrations in both groups (Fig. 2). In the overnight fasted group a further gradual rise was observed, while no change

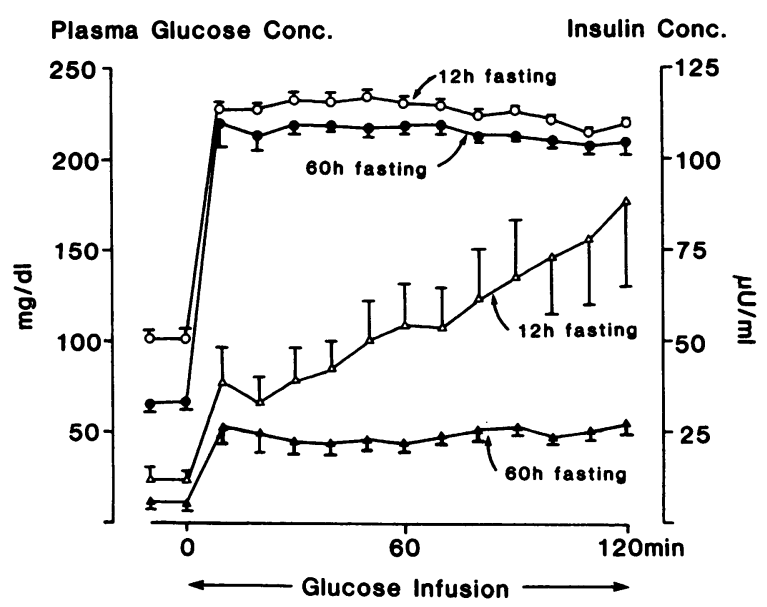

Figure 2. Plasma glucose and serum insulin concentrations in the basal state and during a hyperglycemic glucose clamp after $12 \mathrm{~h}$ and $60 \mathrm{~h}$ of fasting. occurred in the 60-h fasted subjects. The individual responses in the 12-h fasted group varied considerably (Fig. 2), but in spite of this the mean insulin values during the second hour were significantly (almost threefold) higher $(P<0.05)$ than in the $60-\mathrm{h}$ fasted subjects. The total amount of glucose metabolized was $2.62 \pm 0.39 \mathrm{mg} / \mathrm{kg}$ per min in the 60 -h fasted state and $5.38 \pm 1.28 \mathrm{mg} / \mathrm{kg}$ per $\mathrm{min}$ in the 12 -h fasted state $(0.05$ $<P<0.10$ ).

Splanchnic glucose exchange switched in both groups from a net production in the basal state to a net uptake within 10 min after the start of hyperglycemia (Table I, Fig. 1). During the second hour of hyperglycemia, the average splanchnic glucose uptake was much the same in the two groups (60-h fast, $1.26 \pm 0.20,12-\mathrm{h}$ fast, $1.13 \pm 0.23 \mathrm{mg} / \mathrm{kg}$ per min). Peripheral glucose uptake during hyperglycemia (calculated as the difference between total glucose disposal and splanchnic glucose uptake) was $1.42 \pm 0.36 \mathrm{mg} / \mathrm{kg}$ per min after $60 \mathrm{~h}$ of fasting and $4.25 \pm 1.33 \mathrm{mg} / \mathrm{kg}$ per $\mathrm{min}$ in the 12-h fasted group $(0.05$ $<P<0.10)$.

In accordance with observations from in the euglycemic insulin clamp, the splanchnic uptake of lactate fell (NS) and the arterial lactate concentration rose $(P<0.05)$ in the $12-\mathrm{h}$ fasted state, whereas hyperglycemia failed to alter these variables in the $60-\mathrm{h}$ fasted subjects, resulting in lower arterial concentrations and a higher splanchnic uptake of lactate (both $P$ $<0.05$ ) in the 60 -h fasted state. Pyruvate, glycerol, acetoacetate, and 3-OH-butyrate were measured only in the 60 -h fasted state. The arterial concentration and splanchnic uptake of pyruvate and glycerol remained at the basal level during glucose infusion. Splanchnic acetoacetate production fell significantly, while 3-OH-butyrate production was completely inhibited. The arterial acetoacetate and 3-OH-butyrate concentrations fell by $40 \%(P<0.05)$ and $60 \%(P<0.01)$, respectively, in response to hyperglycemia. Estimated splanchnic blood flow was not influenced by hyperglycemia in either group.

\section{Discussion}

In agreement with previous studies (7), the present results demonstrate that starvation for as short a period as $60 \mathrm{~h}$ elicits insulin resistance. Thus, the amount of glucose metabolized in response to hyperinsulinemia, either alone or with concomitant hyperglycemia, was smaller after $60 \mathrm{~h}$ of fasting than after an overnight fast (Table I). With the present experimental design, comprising simultaneous measurements of total glucose 
disposal and net splanchnic glucose exchange, it was possible to determine the contribution of peripheral tissues to this insulin resistance. Since net splanchnic glucose uptake in response to hyperinsulinemia was unaffected by fasting (Fig. 1), the reduced glucose disposal could be attributed to a decrease in the peripheral uptake of glucose (Table I). Similarly, fasting for $60 \mathrm{~h}$ failed to influence the hyperglycemia-induced changes in net splanchnic glucose exchange (Fig. 1), while the peripheral glucose uptake was slightly, though not significantly, lower than after an overnight fast (Table I). Thus, based on these findings we conclude that the decreased ability of insulin to enhance glucose uptake in prolonged fasting is entirely localized to the peripheral tissues. This is in accordance with recently reported results obtained in patients with impaired glucose tolerance (20) and type II diabetes (21). In both cases, an altered insulin-mediated peripheral but not splanchnic glucose metabolism was demonstrated. Available data thus indicate that glucose intolerance, whether induced by a period of fasting in healthy subjects or seen in patients with impaired glucose tolerance and type II diabetes, is primarily the consequence of an impaired glucose uptake by peripheral tissues.

It should be noted that the present study does not allow a quantitation of the extent to which changes in hepatic glucose production and splanchnic glucose uptake contributed to the observed alterations in the net splanchnic glucose balance. Therefore, a comparison between prolonged fasted and overnight fasted individuals regarding splanchnic glucose uptake must rely on an assumed response of hepatic glucose production to hyperinsulinemia. While previous studies have demonstrated a complete suppression of hepatic glucose production in response to hyperinsulinemia in overnight fasted subjects (8), corresponding information from studies in the 60 -h fasted state is lacking. The possibility that hepatic glucose production was not totally suppressed during the clamps in the prolonged fasted subjects must therefore be considered. This is emphasized by a recent study in humans demonstrating that insulin resistant states may be associated with incomplete suppression of endogenous glucose production during hyperinsulinemia (22). Furthermore, studies in dogs have shown that insulin is less potent in inhibiting hepatic gluconeogenesis, the primary source for glucose production in fasting, as compared with its impact on hepatic glycogenolysis (23). Thus, since hepatic glucose production may not have been completely suppressed during the clamps in the 60 -h fasted state but most likely was so in the overnight fasted subjects, the similar values on net splanchnic glucose uptake in the two groups do not necessarily indicate similar true splanchnic glucose uptakes. The present data could also be interpreted as representing only a partial suppression of hepatic glucose production and an increased splanchnic glucose uptake in response to hyperinsulinemia in prolonged (as compared with overnight) fasting. Consequently, the possibility that prolonged fasting is accompanied by a reduction of insulin's suppressing effect on hepatic glucose production cannot be disregarded. However, if this were the case, this must have been accompanied by an augmented splanchnic glucose uptake, since net splanchnic glucose uptake was similar to that in the overnight fasted subjects. These considerations indicate that even though an altered effect of insulin on splanchnic glucose metabolism during prolonged fasting could not be totally excluded, it does not contribute to the glucose intolerance observed in starvation.

Prolonged fasting is accompanied by almost complete exhaustion of the hepatic glycogen stores. After refeeding, these depots are rapidly restored to values above the basal level (2). A similar depletion of the glycogen stores in muscle greatly stimulates muscle uptake of infused glucose and its conversion to glycogen $(9,10)$. Although the phosphorylation of glucose to glucose-6-phosphate, which may be rate limiting, is stimulated by different enzymes in muscle (hexokinase) and liver (glucokinase), one might expect a fasting-induced hepatic glycogen depletion to result in an augmented splanchnic glucose uptake during glucose infusion. However, $60 \mathrm{~h}$ of fasting failed to alter net splanchnic glucose exchange during both hyperglycemia and hyperinsulinemia. Thus, in contrast to the response of muscle, insulin- and/or glucose-stimulated net glucose uptake by splanchnic tissues is not influenced by the glycogen content.

In recent years it has been suggested that glucose per se is a poor precursor for hepatic glycogen synthesis, and that gluconeogenic substrates, primarily lactate, play a more important role in that respect $(24,25)$. The present findings suggest that the rate of hepatic glycogen synthesis from gluconeogenic precursors may be accelerated in prolonged fasting. Thus, apart from splanchnic uptake of glycerol, which decreased during the euglycemic clamp, the uptake of glucogenic precursors remained unchanged during the clamps in the 60-h fasted subjects, contrasting to the decreased precursor uptake observed in the overnight fasted groups (Tables II and III). Thus, based on the assumption that hepatic glucose production is signifcantly if not totally suppressed during hyperinsulinemia in both groups of subjects, the higher uptake of gluconeogenic precursors observed in prolonged fasting is compatible with an increased rate of glycogen synthesis from gluconeogenesis.

In the hyperglycemic glucose clamp, the glucose-stimulated insulin secretion was significantly reduced in the 60 -h fasted subjects, as indicated by a lesser mean rise in insulin values (Fig. 2), thus confirming earlier findings in both animals (6) and humans (7). The insulin values during the second hour of hyperglycemia displayed extremely small variations between subjects in the 60-h fasted group (range 20-32 $\mu \mathrm{U} / \mathrm{ml}$ ), while the variability in the other group was considerable. In spite of these differences the data demonstrate that $60 \mathrm{~h}$ of starvation is accompanied by a consistent inhibition of glucose-stimulated insulin secretion, thus contributing to the glucose intolerance seen during fasting.

\section{Acknowledgments}

This work was supported by the Swedish Society of Medical Sciences, the Nordic Insulin Foundation, and the Tore Nilsson Medical Foundation.

\section{References}

1. Nilsson, L., P. Furst, and E. Hultman. 1973. Carbohydrate metabolism of the liver in normal man under varying dietary conditions. Scand. J. Clin. Lab. Invest. 32:331-337.

2. Nilsson, L., P. Furst, and E. Hultman. 1973. Liver glycogen in man-the effect of total starvation or a carbohydrate poor diet followed by carbohydrate refeeding. Scand. J. Clin. Lab. Invest. 32:325-330.

3. Garber, A. J., P. H. Menzel, G. Boden, and O. E. Owen. 1974. Hepatic ketogenesis and gluconeogenesis in humans. J. Clin. Invest. 54:981-989.

4. Wahren, J., S. Efendic, R. Luft, L. Hagenfeldt, O. Björkman, and P. Felig. 1977. Influence of somatostatin on splanchnic glucose 
metabolism in postabsorptive and 60-hour fasted humans. J. Clin. Invest. 59:299-307.

5. Lilavivathana, U., R. G. Campbell, and R. G. Brodows. 1978 Control of insulin secretion during fasting in man. Metab. Clin. Exp. 27:815-821.

6. Joost, H. G., and J. Beckmann. 1980. On the relation of glucose and insulin secretion in the fasting state. Metab. Clin. Exp. 29:23-27.

7. Newman, W. P., and R. G. Brodows. 1983. Insulin action during acute starvation: evidence for selective insulin resistance in normal man. Metab. Clin. Exp. 32:590-596.

8. DeFronzo, R. A., E. Ferrannini, R. Hendler, P. Felig, and J. Wahren. 1983. Regulation of splanchnic and peripheral glucose uptake by insulin and hyperglycemia in man. Diabetes. 32:35-45.

9. Roch-Norlund, A. E., J. Bergström, and E. Hultman. 1972. Muscle glycogen and glycogen synthetase in normal subjects and in patients with diabetes mellitus: effect of intravenous glucose and insulin administration. Scand. J. Clin. Lab. Invest. 30:77-84.

10. Maehlum, S. 1978. Muscle glycogen synthesis after a glucose infusion during post-exercise in diabetic and non-diabetic subjects. Scand. J. Clin. Lab. Invest. 38:349-354.

11. DeFronzo, R. A., J. D. Tobin, and R. Andres. 1979. Glucose clamp technique: a method for quantifying insulin secretion and resistance. Am. J. Physiol. 237:E214-E223.

12. Bradley, S. E., E. J. Ingelfinger, G. P. Bradley, and J. J. Curry. 1945. The estimation of hepatic blood flow in man. J. Clin. Invest. 24:890-897.

13. Cherick, G. R., S. W. Stein, C. M. Leevy, and S. Davidson. 1960. Indocyanine green: observations on its physical properties, plasma decay and hepatic extraction. J. Clin. Invest. 39:529-600.

14. Huggett, A. S. G., and D. A. Nixon. 1957. Use of glucose oxidase, peroxidase, and $\boldsymbol{O}$-dianisidine in determination of blood and urinary glucose. Lancet. II:368-370.

15. Hohorst, H. J. 1970. $L-(+)$-laktat: bestimmung mit lactat- dehydrogenase und NAD. In Methoden der Enzymatische Analyse. H. U. Bergmeyer, editor. Verlag Chemie, Weinheim. 142.

16. Bucher, R., R. Czok, W. Lamprecht, and E. Latzko. 1962. Pyruvate. In Methoden der Enzymatische Analyse. H. U. Bergmeyer, editor. Verlag Chemie, Weinheim. 253.

17. Wieland, O. 1962. Glycerin. In Methoden der Enzymatische Analyse. H. U. Bergmeyer, editor. Verlag Chemie, Weinheim. 211.

18. Williamson, D. H., J. Mellanby, and H. A. Krebs. 1962. Enzymatic determination of $D(-)-\beta$-hydroxybutyric acid and acetic acid in blood. Biochem. J. 82:90-96.

19. Snedecor, G. W., and W. G. Cochran. 1967. Statistical Methods. Iowa State University Press, Ames, lowa. Sixth ed. 593 pp.

20. Sacca, L., G. Orofino, A. Petrone, and C. Vigorito. 1984. Differential roles of splanchnic and peripheral tissues in the pathogenesis of impaired glucose tolerance. J. Clin. Invest. 73:1683-1687.

21. DeFronzo, R., R. Gunnarsson, O. Björkman, and J. Wahren. 1982. Peripheral tissues are responsible for the insulin resistance in type 2 (non-insulin dependent) diabetes mellitus. Diabetologia. 23:163. (Abstr.)

22. Ravussin, E., C. Bogardus, R. S. Schwartz, D. C. Robbins, R. R. Wolfe, E. S. Horton, E. Danforth, Jr., and A. H. Ethan. 1983. Thermic effect of infused glucose and insulin in man. Decreased response with increased insulin resistance in obesity and noninsulindependent diabetes mellitus. J. Clin. Invest. 72:893-902.

23. Chiasson, J. L., J. E. Liljenquist, F. E. Finger, and W. W. Lacy. 1976. Differential sensitivity of glycogenolysis and gluconeogenesis to insulin infusions in dogs. Diabetes. 25:283-291.

24. Radziuk, J. 1981. Glucose and glycogen metabolism following glucose ingestion in man: a turnover approach. In Carbohydrate Metabolism. C. Cobelli and R. N. Bergman, editors. John Wiley \& Sons, Inc., New York. 239-266.

25. Shikima, H., and M. Ui. 1978. Glucose load diverts hepatic glucogenic product from glucose to glycogen in vivo. Am. J. Physiol. 235:E354-E360. 